九州大学学術情報リポジトリ

Kyushu University Institutional Repository

Extracorporeal Shock Wave Lithotripsy Monotherapy for Staghorn Calculi

山口，秋人

https://doi.org/10.11501/3099971

出版情報：九州大学，1994，博士（医学），論文博士 バージョン：

権利関係 : 


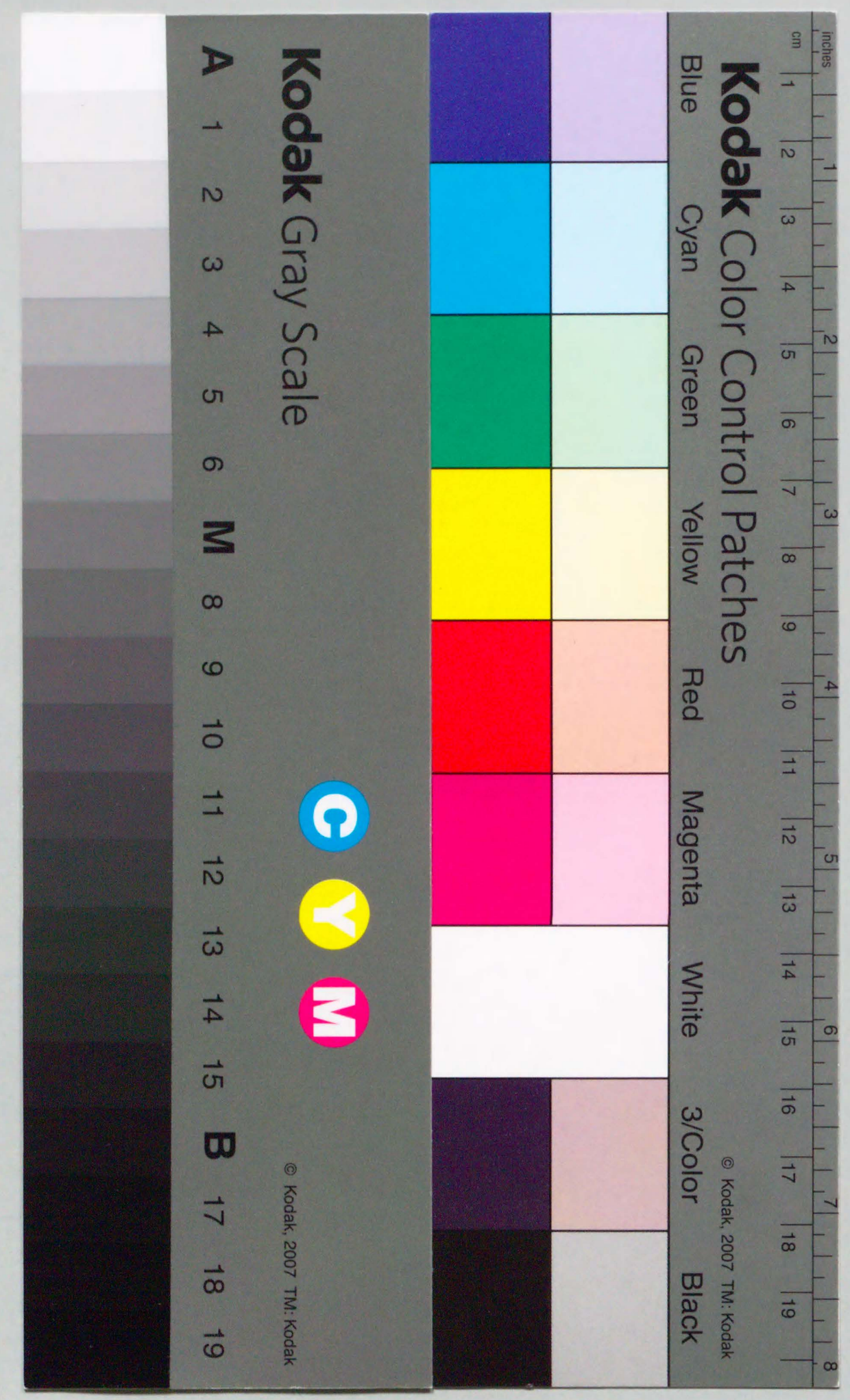

Akito Yamaguchi

Division of Urology, Sanshinkai Ha
Hospital. Fukuoka . anpan
European

Editor-in-Chief

Reprint

Reprint
Eur Urol 1994:25:110-11:

\section{Extracorporeal Shock Wave}

Lithotripsy Monotherapy for

Staghorn Calculi 

ESWL was thus considered to have been fairly effective in the present series. The remaining 9 cases $(30 \%)$ contained a considerable amount of residuals (more than $100 \mathrm{~mm}^{2}$ ). The present study in the ESWL of large staghorn calculi revealed no clear relationship between the surface area of the stones and evacuation of the fragments. The amount of the residual fragments was significantly small when either the renal collecting system was less than $2,000 \mathrm{~mm}^{2}$ in area $(p<0.05)$, or when the ureteropelvic junction (UPJ) was equal or greater than $5 \mathrm{~mm}$ in diameter $(\mathrm{p}<0.02)$ according to intravenous pyelography (IVP) before treatment. The conplications associated with this treatment were minimal, with a high fever in only 3 patients that were treated easily by antibiotic therapy. ESWL monotherapy thus appears to be effective for the treatment of staghorn calculi, while causing few complications. Thus, cases showing less than $2,000 \mathrm{~mm}^{2}$ in area for the collecting system or those showing an equal to or greater than $5 \mathrm{~mm}$ diameter of UPJ on IVP before treatment, are all 列 
We have treated patients with variegated renal calculi since 1986. Among them, we have analyzed the success ates for the treatment of staghorn calculi in association wh the py is truly an effective alternative for the treatment of is py s a retrospective analysis of ESWL mo for this h our ESWL center was conducted as described herein

\section{Materials and Methods}

For 2 years from April 1988 to March 1990, 69 cases were diaglosed as having large staghorn calculi, more than $35 \mathrm{~mm}$ in maxi bined with percutancous nephrolithotomy $(\mathrm{PNL})$, and 4 were treated with PNL alone. Subsequently, 48 patients were treated with ESWL monotherapy. However, 18 were discarded from the study, becausc . those 12 patients had been missed. Follow-up study was too short for 6 patients when the study period was closed. Finally, 30 patients were admitted to this study.

The mean observation period was 12.9 months. Other than the 48 patients mentioned above, 17 were treated with ESWL in combina-
lion with PNL and 4 were treated with PNL alone. The 30 other patients studied consisted of 21 complete and 9 partial staghorn calculi, as show in table 1 , consisting of 10 males and 20 remales. Their mean age was 50.8 years, ranging from 28 to 72 years. The calculi patients. Both before and after treatment, an IVP was routinely adopted to visualize the anatomical structure of the upper urinary tract. The angle formed with the medial silhouette line of the ureter (UPA-A). Similarly, the UPA-B was measured using the lateral line of the ureter and an inferior line of the renal pelvis. The areas of stones were measured on plain X-ray films. Measurements wer recorded using an Image analyzing system (Cosmozone $2 S$, Nikon,
Tokyo, Japan). The angles and areas obtained in this way were taken into consideration as factors that would influence the results of the treatment. According to previous reports [7], a $6 \mathrm{~F}$ ureteral stent was placed prior to ESWL in all patients. For the initial ESWL treatment, MM.3 wasu plain X-ray film and IVPs both before and after treatmen.

\section{Results}

As shown in table 2, the maximal lengths of the calculi anged from 35 to $94 \mathrm{~mm}$ (the mean value was $61 \mathrm{~mm}$ ). The area of calculi obtainedron the standard anteropos$2,91 \mathrm{~mm}^{2}$ (with plain $\mathrm{X}$-ray film ranged from 447 to

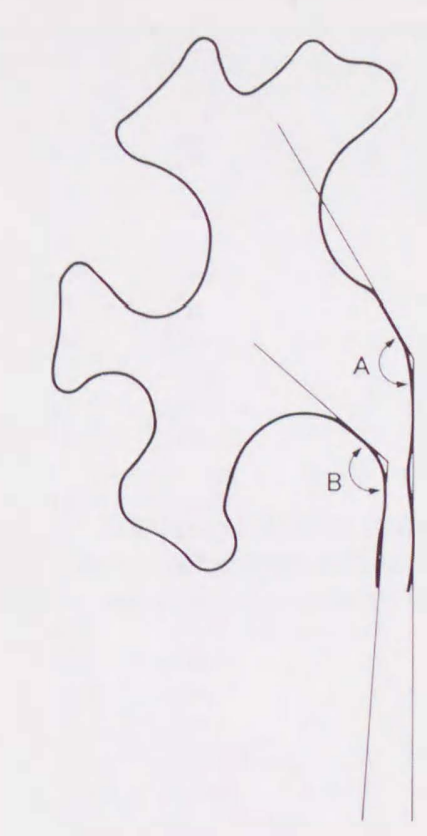
Fig. 1. Scheme used for measurement

Table 1. Thirty patients (age $28-72$ mean 50.8) with large staghorn calculi treated by ESWL monotherapy

\begin{tabular}{llr}
\hline Sex & male & 10 \\
& female & 20 \\
Side & right & 16 \\
& left & 14 \\
Type & complete & 21 \\
& partial & 9 \\
& &
\end{tabular}

he collecting system, as measured from the IVPs, ranged from 947 to $3,943 \mathrm{~mm}^{2}$ (with a mean value of $2,200 \mathrm{~mm}^{2}$ ). The average angle which formed at the medial silhouette line of the ureter and superior silhouette line of the renal pelvis was $178.4^{\circ}$ at the UPJ (UPA-A), while the average for the UPA-B measured using a lateral ine of the ureter and inferior line of the renal pelvis was 38.1. The mean difference in angles between the UPA$A$ and the UPA-B was $40.3^{\circ}$. After the last $E S W L$, the patients were observed for 6 to 29 months (mean dura-
tion: 13.0 months). At the last observation, the area of 
Table 2. Measurements of large staghorn
calculi on plain X-ray film and the collectcalculi on plain X-
ing system on IVP

\begin{tabular}{lcc}
\hline Maximum length of the calculi, $\mathrm{mm}$ & $35-94$ & $(61)$ \\
Area of the calculi, mm ${ }^{2}$ & $447-2,910$ & $(1,270)$ \\
Area of the collecting system, $\mathrm{mm}^{2}$ & $947-3,943$ & $(2,200)$ \\
Diameter of the PUJ, mm & $1-14$ & $131 .-14$ \\
Angle of the UPA-A & $131.3-227.6^{\circ}$ & $(178.4)$ \\
Angle of the UPA-B & $82.9-170.8^{\circ}$ & $(138.1)$ \\
Difference hetween the UPA-A and the UPA-B & $-1.3-113.1^{\circ}$ & $(40.3)$ \\
\hline Mean values in parentheses. & &
\end{tabular}

Table 3. Correlation of residual fragments and the measurements on $X$-ray
film taken before treatment (mean \pm SD)

\begin{tabular}{|c|c|c|c|c|}
\hline Measurements & Range & Patients & Area of the $\mathrm{ft}$ & gments, $\mathrm{mm}^{2}$ \\
\hline Area of the calculi & $\begin{array}{l}<1,000 \mathrm{~mm}^{2} \\
>1,000 \mathrm{~mm}^{2}\end{array}$ & $\begin{array}{l}13 \\
17\end{array}$ & $\left.\begin{array}{l}0.60 \pm 0.80 \\
1.98 \pm 3.19\end{array}\right\}$ & n.S. \\
\hline Area of the collecting system & $\begin{array}{l}<2,000 \mathrm{~mm}^{2} \\
>2,000 \mathrm{~mm}^{2}\end{array}$ & $\begin{array}{l}13 \\
17\end{array}$ & $\begin{array}{l}0.27 \pm 0.45 \\
2.24 \pm 3.11\end{array}$ & $\mathrm{p}<0.05$ \\
\hline Diameter of the PUJ & $\begin{array}{l}<5 \mathrm{~mm} \\
\geqq 5 \mathrm{~mm}\end{array}$ & $\begin{array}{l}12 \\
18\end{array}$ & $\left.\begin{array}{l}2.67 \pm 3.56 \\
0.53 \pm 0.78\end{array}\right\}$ & $\mathrm{p}<0.02$ \\
\hline Area of the UPA-B & $\begin{array}{l}<140^{\circ} \\
\geqq 140^{\circ}\end{array}$ & $\begin{array}{l}15 \\
15\end{array}$ & $\left.\begin{array}{l}0.94 \pm 1.54 \\
1.83 \pm 3.21\end{array}\right\}$ & n.s. \\
\hline $\begin{array}{l}\text { Difference between the } \\
\text { UPA-A and UPA-B }\end{array}$ & $\begin{array}{l}<45^{\circ} \\
\geqq 45^{\circ}\end{array}$ & $\begin{array}{l}19 \\
11\end{array}$ & $\left.\begin{array}{l}1.23 \pm 2.15 \\
165+3.12\end{array}\right\}$ & n.s. \\
\hline
\end{tabular}

residual calculi on plain X-ray ranged from 0 to number of sessions averaged 3.7, ranging from 1 (4 , $115 \mathrm{~mm}^{2}$. The mean value plus SD was $138.3+$ patients) to $8(1$ patient). The mean total number of shoc . 作 . (00 $100 m^{2}$. Table 3 shows the relationship between 作 sis of the X-rays taken before treatment The information had improved, and then were rehospitalized when residuincluded the areas of the calculi, the area of the collecting al small fragments were spontaneously eliminated and system, the diameter of the UPJ, the UPA-A and the only large ones remained. The number of hospitalizations UPA-B and the differences between the UPA-A and the ranged from 1 to 5 . The total period of hospitalization UPA-B. A significant correlation could be noticed in the varied from 13 to 136 days (mean 55.2 days). As an addirea of the collecting system and the diameter of the UPJ tional therapy, transurethral ureterolithotripsy (TUL) wa in relation to the residual stone rate. Namely, in cases adopted in order to get rid of the arrested fragments of showing the area of the collecting system to be less than broken calculi.

$2,000 \mathrm{~mm}^{2}$, the amount of residual stones was significant- Results of stone analysis showed predominance of ly smaller than that in cases showing an area of over infectious stones (56.7\%), which included struvites, car$2,000 \mathrm{~mm}^{2}(\mathrm{p}<0.05)$. In addition, in cases showing a bonate apatite and hydroxyl apatite. Oxalate stones were diameter of the UPJ equal to or more than $5 \mathrm{~mm}$, the second in frequency (33.3\%) as shown in table 5 . No amount of residual stones was significantly smaller than patients with cystine stones were treated. No significant the ESWL treatment by HM3 are shown in table 4. The tion and evacuation of the stones.
Table 4. Paticnts treated hy ESWL monotherany

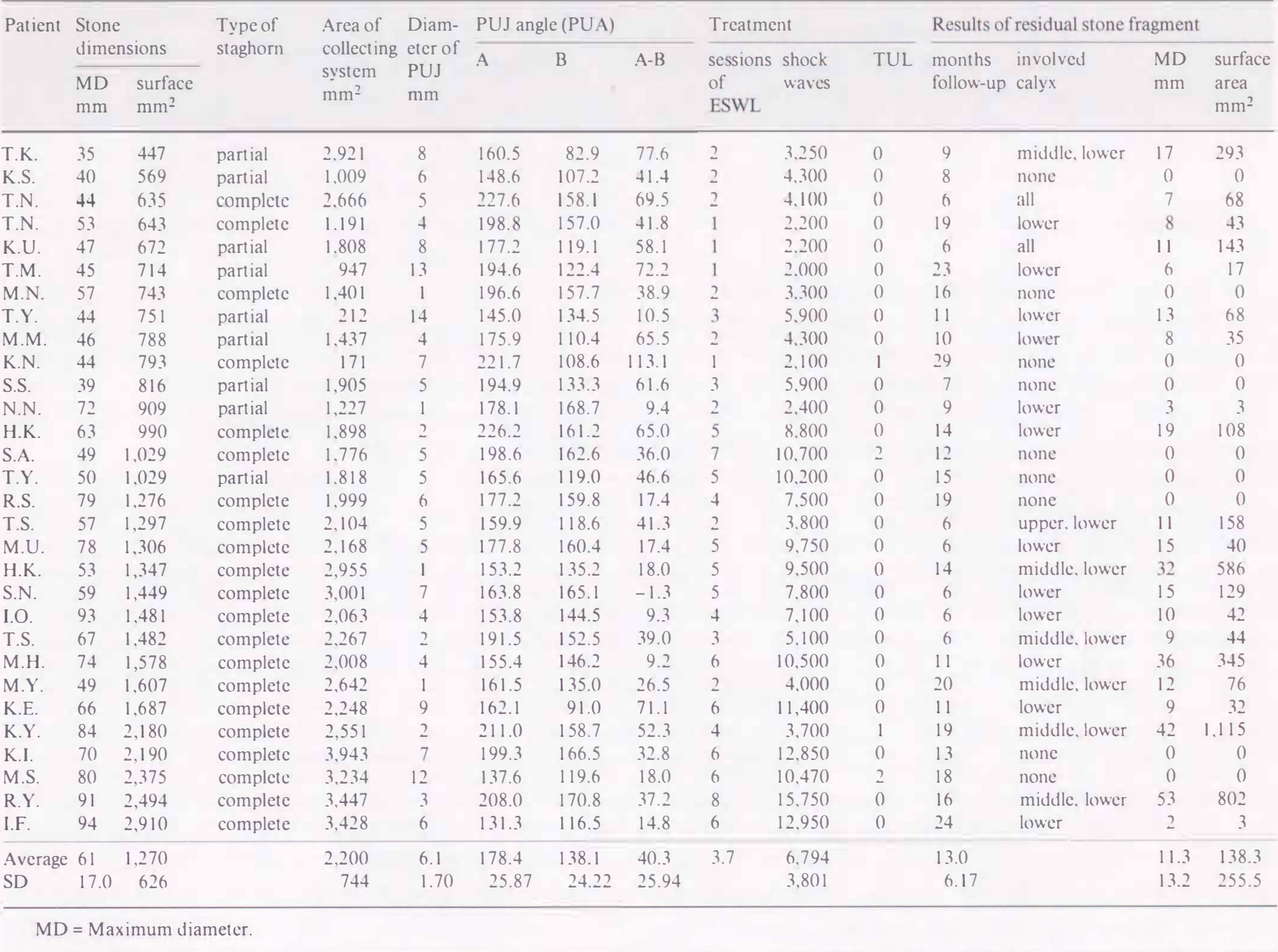

The most frequent complication was a high fever of over $38^{\circ} \mathrm{C}$, which was seen in 3 patients. The fevers were
easily controlled, however, with antibiotic therapy. No subcapsular hematoma was encountered although ultrasonographic examinations were carried out on all patients both before and after treatment. Before treatment, there were 27 patients $(90.0 \%$ ) with mild pyuria (a leukocyte count, over $5 / \mathrm{hpf}$ ), and 16 patients (53.3\%) with severe pyuria (massive leukocytes). After ESWL treatment, 12 of 16 cases of severe pyuria improved, while 4 patients still demonstrated persistent severe pyuria. Regarding urine

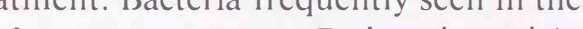
a 4 cases and Protens mirabilis in 4 cases. Serratia marcescus and Flavobacterium were encountered in 1 case respectively, while 2 cases of nonfermentative bacteri tected in 1 patient and S. marcescens in another.
Table 5. Analysis of stone composition

\begin{tabular}{lc}
\hline Infection-related' $^{1}$ & $17(56.7)$ \\
Calcium oxalate & $10(33.3)$ \\
Uric acid & $1(3.3)$ \\
Unknown & $2(6.7)$ \\
\hline
\end{tabular}

Includes struvite, carbonate apatite, hydroxyl apatite 
As for rerial function, BUN and creatinine were exam- tract infection improved, and such factors support the

ned both before and after treatment. The mean value \pm evidence that ESWL monotherapy is a highly effective SD of BUN was $13.5 \pm 4.5 \mathrm{mg}$ dl before treatment and $12.6 \pm 3.9 \mathrm{mg} / \mathrm{d}$ after treatment, while that of creatinine was $0.81 \pm 0.22$ and $0.73+0.24 \mathrm{mg} / \mathrm{dt}$. Neither of the differences were statistically significant.

\section{Discussion}

Concerning the treatment of renal staghorn calculi, the total elimination rate of residual stones in the presen study seemed to be inferior to previous reports [5-7]. This may be attributable to our subjects having comparatively larger staghorn calculi than reported elsewhere. Yet, we attained a total disappearance of the calculi in $9(30 \%)$ ou of 30 cases. The longest diameter of the residual fragments has been taken into account previously for he success rate of ESWL therapy $[3,8,9]$. However, it seeme very difficult to calculate the longest diameter of the residual fragments, because most of the residual fragments had accumulated into the lower calyces after ESWL therapy, which made it hard to measure the largest fragments among them. In addition, it seemed much more appropriate to measure the total volume of the residual stones.
However, it was also very difficult and complicated to However, it was also very difficult and complicated to cere ness of the ments on plain $X$ rays. By this method, it was found in 12 cases (49\%) that the anount of residual fragents was mall, less than $100 \mathrm{~mm}^{2}$. Adding these cases to those in which all the residual calculi were eliminated the tota urned out to be 21 cases $(70 \%)$ and thus the treatment taghorn calculi with ESWL was considered to h fairly effective in the present series.

Some authors have reported that ESWL treatmen became more effective when PNL was combined with ESWL for the treatment of staghorn calculi $[10,11]$, but the additional PNL did not seem to shorten the hospital stay. Moreover, it has been said that treatment by ESWL alone was less likely to bother the patients [5], whereas Miller et al. [12] reported that ESWL combined with PNL showed a higher stone-free rate than ESWL monotherapy.

In the present cases, there were no complications of subcapsular hematomas. Only 3 cases were suspected of having urosepsis with a high fever, but none of the required PNS. They all recovered with conservative treament. In most of the present cases, a concomitant urinary The remedy for staghorn calculi.

The common understanding that is now generally accepted is that the size of the calculi before treatment plays a major role in determining the efficacy of ESWL In the present series, however, there was little correlation regarding the size of the calculi before treatment, which was in agreement with the report of Gleeson and Griffith 8]. Using an image analyzing system, Lam et al. [13] stated that stone surface area provided a useful basis to predict the possibility of evacuation and to compare the data among the institutions. However, the present study in the ESWL of large staghorn calculi revealed no clear relationship between the surface area of the stones and evacuation of the fragments.

Before this study, we supposed that the blunter the ngle between he renal pelvis and long axis of the treter was made, the easier was the predicted evacuation of the ealeuli. However, as far as we could determine, hiere was o significant correlation between the angles and the The of the calculi evacuated.

The prognosis of patients treated with ESWL has been considered to vary widely depending upon the shape of the renal calculi and the renal collecting system. There fave, however, only pelvis a reat per exceded $2000 \mathrm{~mm}^{2}$. Di Silverio et al. [11] reported that ESWL monotherapy was recommended in patients with no dilatation of renal pelvis or calyces. They abo recommended ESWL combined with PNL in patients with dilaton in which over 70\% of the calculi could be removed through a single tract. If the removal of $70 \%$ or more by his method was presumed difficult, surgical operation was the next alternative [11]. In both reports, the relationships between the concrete measured values and the amount of residual stones were not shown. From the above data, we considered that the determining factors for the result of treatment were the size, shape and components of calculi, their location, as well as the function of the pelvis and the shape of the upper urinary tract.

In the present study, we examined the changes in the X-rays both before and after ESWL to look for any correlation among the shape of the renal pelvis, as well as the alt culi. The resuls showed that the evect of treatment had more to do with the size of the pelvis and calyces as well as
he diameter of the UPJ than with the size of the calculi.
That is, in cases in which the area of the pelvis and calyces were over $2,000 \mathrm{~mm}^{2}$ or where the diameter of the UPJ was less than $5 \mathrm{~mm}$, the andy seemed to be significantly large, and the treatment by icient result. Therefore, the combined technique of PNL seems worthy of consideration for those cases mentioned

\section{References}

1 Chaussy C, Schmiedt E, Jocham D, Brendel W,
Forssmann B, Walther V: First clinical cel wer. ence with extracorporeally indued destrect of kidney stones by shock waves. J U rol 1982 Higashihara E, Kishi H, Umeda T, Isurugi K,
Niiima T: The with extracorporeal shock wave lithotripter. sis. Jpn J Urol 1 $1986: 77: 1416-1420$.
s.t. 3 Karlsen S, Gjoelberg T: Branched renal calcul extracorporeal shock waves. Scand I Urol 1989:23:201-205.
Puppo P. Bottino P, Germinale F, Caviglia C Ricciotiti G, Giuliani L: Percutaneous debul ing of staghorn stones combined with extraco-
poreal shock wave lithotripss: Results an

\section{Acknowledgments}

A part of this paper was presented at the $42 n d$ Annual Meeting of Urological Society.

lam deeply indebted to Prof. Joichi Kumazawa, Department of
rology. Faculty of Medicine. Kyushu University for his sugge also thank Miss Minako Nagai for her
Whicicld HN, Clayman RV, Chaussy CG, 10 Pode D. Verstandig A. Shapiro A. Kaz

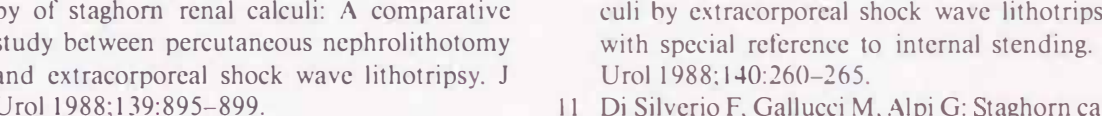
Vandeursen stones with the second gencraption lor stighoghor J Urol 1990; 143:252-256. Extracorpendes, Recker F, Jaeger P, Hauri D monotherapy of staghorn renal calculi: 3 years
of experience. J Urol 1989:142:1415-1418. wave lithotripsy monotherany for large reen calculi. Br I Urol 1989:64:329-332. Bosshe MV. Simon J, Schulman CC: Shock
wave monotherapy of staghorn calculi. Eur Wrol 1988: $140: 260-265$.

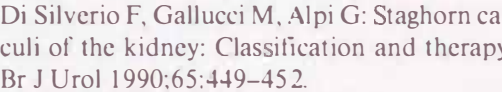
Miller K, Bachor R, Hautmann R: Percute

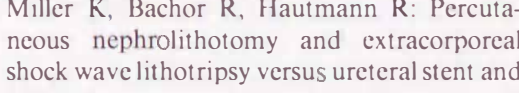
SWWL for the treatment of large renal calc zed study: Preliminary results. J Endour 1988:2:131-135.
Lam HS, Lingeman JE, Russo R, Chua GT Stone surface area determination techniques: unifying concept of traghorn stone burden as
scssment. J Urol 1992:148:1026-1029 
